\title{
Glucose intolerance and gestational diabetes risk in relation to sleep duration and snoring during pregnancy: a pilot study
}

\author{
Chunfang Qiü¹, Daniel Enquobahrie1,2, Ihunnaya O Frederick1, Dejene Abetew¹ and Michelle A Williams',2
}

\begin{abstract}
Background: Insufficient sleep and poor sleep quality, considered endemic in modern society, are associated with obesity, impaired glucose tolerance and diabetes. Little, however, is known about the consequences of insufficient sleep and poor sleep quality during pregnancy on glucose tolerance and gestational diabetes.

Methods: A cohort of 1,290 women was interviewed during early pregnancy. We collected information about sleep duration and snoring during early pregnancy. Results from screening and diagnostic testing for gestational diabetes mellitus (GDM) were abstracted from medical records. Generalized linear models were fitted to derive relative risk (RR) and $95 \%$ confidence intervals ( $95 \% \mathrm{Cls}$ ) of GDM associated with sleep duration and snoring, respectively.

Results: After adjusting for maternal age and race/ethnicity, GDM risk was increased among women sleeping $\leq 4$ hours compared with those sleeping 9 hours per night ( $R R=5.56 ; 95 \% \mathrm{Cl} 1.31-23.69)$. The corresponding $\mathrm{RR}$ for lean women $\left(<25 \mathrm{~kg} / \mathrm{m}^{2}\right)$ was $3.23(95 \% \mathrm{Cl} 0.34-30.41)$ and 9.83 ( $\left.95 \% \mathrm{Cl} 1.12-86.32\right)$ for overweight women ( $\left.\geq 25 \mathrm{~kg} / \mathrm{m}^{2}\right)$. Overall, snoring was associated with a 1.86 -fold increased risk of GDM (RR $=1.86 ; 95 \% \mathrm{Cl}$ 0.88-3.94). The risk of GDM was particularly elevated among overweight women who snored. Compared with lean women who did not snore, those who were overweight and snored had a 6.9-fold increased risk of GDM (95\% Cl 2.87-16.6).

Conclusions: These preliminary findings suggest associations of short sleep duration and snoring with glucose intolerance and GDM. Though consistent with studies of men and non-pregnant women, larger studies that include objective measures of sleep duration, quality and apnea are needed to obtain more precise estimates of observed associations.
\end{abstract}

\section{Background}

Insufficient sleep duration and poor sleep quality are considered to be endemic in modern society. Findings from epidemiological and animal experimental studies indicate that chronic partial sleep loss is associated with increased risks of obesity and a myriad of obesity-related disorders including impaired glucose tolerance, hypertension, diabetes, metabolic syndrome, coronary heart disease, stroke and premature mortality [1-8]. The impact of short sleep duration on the risk of diabetes has been shown in several epidemiological studies, with significant increases in the incidence of diabetes among individuals who report habitual short sleep duration and those who report

* Correspondence: Chun-fang.Qiu@Swedish.org

${ }^{1}$ Center for Perinatal Studies, Swedish Medical Center, Seattle, Washington, USA

Full list of author information is available at the end of the article having difficulty maintaining sleep [4,9-11]. Moreover, accumulating evidence link habitual snoring and sleep apnea, both part of a spectrum of sleep-related breathing disorders, with cardiometabolic abnormalities that include hypertension, dyslipidemia, obesity, hyperglycemia, insulin resistance and type 2 diabetes [2,7,12-15]. Although the exact mechanisms underlying these associations have yet to be fully elucidated, evidence from experimental studies suggest that insufficient sleep and sleep fragmentation result in metabolic and neuroendocrine alterations, particularly alterations in the hypothalamic-pituitary adrenal (HPA) axis, that may contribute to the development of impaired glucose tolerance, insulin resistance and type 2 diabetes mellitus [16-20]. Moreover, experimental studies in humans [21,22] and animals $[23,24]$ have demonstrated that intermittent hypoxia, 
known to occur in sleep apnea, exerts adverse effects on glucose metabolism. Most sleep studies, however, have excluded pregnant women; hence very little is known about how insufficient sleep and sleep disordered breathing during gestation contribute to increased risks of medical complications of pregnancy including gestational diabetes mellitus (GDM).

To the best of our knowledge no one has evaluated the impact of sleep duration and snoring on maternal glucose metabolism in pregnancy. In this pilot study, we assessed associations of maternal self-reported sleep duration and snoring during early pregnancy with glucose intolerance and a diagnosis of GDM later in pregnancy. We analyzed maternal plasma glucose concentrations 1 hour after a 50 -gram oral glucose challenge as part of routine midpregnancy screening for GDM. We hypothesized that maternal habitual short sleep duration and snoring during early pregnancy were positively associated with post load glucose concentrations later in pregnancy and with an increased risk of clinically diagnosed GDM.

\section{Methods}

\section{Study population and setting}

This preliminary (pilot) study is based on data collected from a cohort of women attending prenatal care clinics affiliated with Swedish Medical Center in Seattle, Washington. The cohort study was designed to evaluate the influence of maternal diet, physical activity and the other life style factors on the occurrence of preeclampsia, gestational diabetes mellitus and other adverse pregnancy outcomes. Eligible women initiated prenatal care before 20 weeks gestation, were 18 years of age or older, could speak and read English, and planned to carry the pregnancy to term and to deliver at either hospital. At 14 weeks gestation, on average, participants reported sociodemographic, behavioral, and health characteristics in a structured interview. After delivery, study personnel abstracted data from participants' hospital labor and delivery medical records and clinic records. Between December 2003 and July 2006, 1,393 (82\%) of 1,685 approached women consented to participate. We sequentially excluded 12 women with early pregnancy losses, 52 who were lost to follow-up, and 23 who did not complete the interview. We also excluded 16 women with pre-gestational diabetes. Thus, 1,290 women remained for analysis. All study procedures were approved by the Institutional Review Board of Swedish Medical Center. All participants provided written informed consent.

\section{Description of covariates}

At the time of enrollment in the study, a 45 to 60 -minute structured questionnaire was administered by a trained interviewer. Information on medical and reproductive histories and sociodemographic and lifestyle characteris- tics including average number of hours of sleep before and during early pregnancy was collected. Maternal average nightly sleep duration during pregnancy was ascertained by asking women the following question: "Since becoming pregnant, how many hours per night do you sleep?" A similar question was asked for sleep duration before pregnancy. Responses were recorded as integers. For bivariate analyses, we classified participants into 4 sleep duration categories: $\leq 4,5-8,9$, and $\geq 10$ hours, respectively. The cut-points were based on categorizations used in prior research $[4,11]$. Given that pregnant women, particularly those in the first trimester, are known to require 30-45 more minutes of sleep per night than their non-pregnant counterparts [25-27], we a priori defined those women who reported sleeping 9 hours per night as the reference group. Sleep disordered breathing during pregnancy was assessed by asking women about the frequency of snoring during the index pregnancy. Specifically they were asked "Since becoming pregnant, when you are asleep, to the best of your knowledge, have you snored?" Responses were as follows: $(i)$ all of the time, (ii) most of the time, (iii) some of the time, (iv) a little of the time, and $(v)$ none of the time. From this information, we categorized participants as snoring if their reported snoring most or all of the time; all other women were classified as non-snorers. Pre-pregnancy weight and height were also based on self-reports made during the interview. Pre-pregnancy body mass index (BMI) was calculated as weight in kilograms divided by height in meters squared.

In our study setting, according to the recommendations from the American Diabetes Association (ADA) [25], all pregnant women were screened at 24-28 weeks gestation using a 50 gram 1-hour oral glucose challenge test. Those patients who failed this screening test (glucose $\geq 140 \mathrm{mg} /$ dl) were then followed-up within 1-2 weeks with a 100 gram, 3-hour oral glucose tolerance test (OGTT). We abstracted laboratory results from participants' 50 gram 1-hour glucose challenge test and from the diagnostic 100 gram 3-hour OGTT. Women were diagnosed with GDM if two or more of the 100 gram OGTT glucose levels exceeded the ADA criteria [28] as follows: fasting $\geq 95$ $\mathrm{mg} / \mathrm{dl}$; 1 -hour $\geq 180 \mathrm{mg} / \mathrm{dl}$; 2 -hour $\geq 155 \mathrm{mg} / \mathrm{dl}$; 3 -hour $\geq$ $140 \mathrm{mg} / \mathrm{dl}$.

\section{Statistical analytical methods}

We compared the frequency distribution of sociodemographic, lifestyle, behavioral and medical history characteristics of participants according to GDM diagnosis status. We assessed glucose intolerance by analyzing results of the 1-hour oral glucose screening test results. Linear regression procedures were used to estimate maternal mean 1-hour glucose concentrations while adjusting for confounding by maternal age and race/eth- 
nicity. We fitted generalized linear models, using a loglink function, to derive relative risk (RR) and 95\% confidence intervals (95\% CIs) [29,30] of the associations between sleep duration and snoring variables with glucose intolerance and GDM risk. Separate models were fitted for sleep duration and snoring. We evaluated confounding due to several maternal characteristics. We selected potential confounders from a list of variables that were associated with sleep duration and snoring (from prior studies conducted among men and non-pregnant women) and that met criteria for confounding based on a review of the literature and assessment of potential causal relationships based on prior knowledge. We then controlled for potential confounders that changed multivariable RRs by more than $10 \%$ relative to the unadjusted RR [31]. On the basis of these criteria, we controlled for maternal age and race/ethnicity. None of the other variables listed in Table 1 were found to be confounders. Gestational age at enrollment or interview was not a confounder in this study. Given that this is the first study to be conducted among pregnant women, and that prepregnancy BMI may reasonably be considered a confounder or a covariate along the causal pathway between maternal habitual sleep behaviors and GDM, we were careful to assess the potential independent contributions of the sleep variables (from pre-pregnancy BMI). The distinction is important because adjustment for covariates along the causal pathway may spuriously attenuate estimates of association. Therefore, we constructed additional models that simultaneously adjusted for prepregnancy BMI. We also reported results after stratification so that we (and readers) could assess associations (even with a fair amount of statistical imprecision) without an over-reliance on model-based assumptions. In keeping with prior studies that sought to assess the extent to which adiposity modified associations between sleep disorders and abnormal carbohydrate metabolism $[1,2,4,5,18]$, we also evaluated the joint effect of pre-pregnancy overweight status and snoring on GDM risk. For these analyses, we classified women by the joint distribution of pre-pregnancy lean or overweight status ( $<25 \mathrm{vs.} \geq$ $25 \mathrm{~kg} / \mathrm{m}^{2}$ ) and snoring during early pregnancy (no vs. yes) thus resulting in the following categories: lean and nonsnorer (the reference group); lean and snorer; overweight and non-snorer; and overweight and snorer. All analyses were performed using Stata 9.0 statistical software (Stata, College Station, TX). All reported p-values are twotailed.

\section{Results}

Approximately $5.3 \%$ of the study cohort developed gestational diabetes mellitus (68 of 1,290). The socio-demographic characteristics of the study cohort (overall and by GDM status), are presented in Table 1. Overall, partici- pants included in this analysis tended to be Caucasian, well-educated, and married. GDM cases were older, and heavier than women who did not develop the disorder. Cases were less likely to be of non-Hispanic White race/ ethnicity than non-cases.

A curvilinear relation was seen across levels of maternal habitual nightly sleep duration in early pregnancy for maternal mean-1 hour plasma glucose concentration after a 50-gram oral glucose challenge during weeks 2428 gestation (Figure 1). Maternal mean 1-hour plasma glucose concentrations, adjusted for age and race/ethnicity, were highest for women who reported habitual sleep duration $\leq 4$ hours per night during early pregnancy and lowest for those who reported sleeping 9 hours per night on average. Mean glucose concentrations 1-hour after a 50 -gram oral glucose challenge were $16.3 \mathrm{mg} / \mathrm{dl}$ higher in women who reported sleeping $\leq 4$ hours (95\% CI 1.131.6, $\mathrm{p}=0.04), 2.3 \mathrm{mg} / \mathrm{dl}$ higher for women who reported sleeping 5-8 hours (95\% CI -1.8-6.3, p = 0.27), and 6.3 $\mathrm{mg} / \mathrm{dl}$ higher for women who reported sleeping $\geq 10$ hours (95\% CI -0.5-13.2, p = 0.07) compared with those who reported sleeping 9 hours per night. The curvilinear relationship remained evident after participants were stratified on the basis of lean $\left(<25 \mathrm{~kg} / \mathrm{m}^{2}\right)$ and overweight $\left(\geq 25 \mathrm{~kg} / \mathrm{m}^{2}\right)$ pre-pregnancy status (Figure $2 \mathrm{a}$ ). As can be seen in Figure $2 b$, the frequency distribution of women with post-50 gram 1-hour glucose concentration $\geq 140$ $\mathrm{mg} / \mathrm{dl}$ (i.e., the threshold for screen positive for glucose intolerance) also had a curvilinear pattern. Regardless of maternal pre-pregnancy overweight status, both short and long sleep durations were associated with higher frequencies of elevated plasma glucose concentrations (Figure $2 \mathrm{~b}$ ). Compared with women who did not snore during pregnancy, the adjusted mean 1-hour glucose concentrations were noted to be $6.4 \mathrm{mg} / \mathrm{dl}$ higher among those women who snored during pregnancy $(\beta=6.4 \mathrm{mg} / \mathrm{dl}, 95 \%$ CI 0.32-12.5, $\mathrm{p}=0.04$ ).

After adjusting for maternal age and race/ethnicity, women who reported sleeping $\leq 4$ hours per night during early pregnancy had a 5.56-fold increased risk of GDM as compared with those women who reported sleeping 9 hours per night (the reference group) $(\mathrm{RR}=5.56$; $95 \% \mathrm{CI}$ 1.31-23.69). The positive association remained, though was attenuated somewhat, after further adjustment for maternal pre-pregnancy BMI $(\mathrm{RR}=4.18$; 95\% CI 0.9418.60). We also noted that associations between short sleep duration and GDM risk were particularly pronounced among overweight women (far right column of Table 2). Given the suggestion of a U-shaped relation between sleep duration and GDM risk (with elevated risks for both short and long sleep duration), and given suggestion of a linear trend in risk of GDM for sleep duration ranging from $\leq 4$ to 5-8 hours, we modeled the risk of GDM in relation to maternal sleep duration as a 


\begin{tabular}{|c|c|c|c|}
\hline & \multirow[b]{2}{*}{$\begin{array}{l}\text { Entire Study Cohort } \\
\qquad N=1290\end{array}$} & \multicolumn{2}{|c|}{ Gestational Diabetes Mellitus } \\
\hline & & $\begin{array}{c}\text { No } \\
N=1222\end{array}$ & $\begin{array}{c}\text { Yes } \\
N=68\end{array}$ \\
\hline Characteristics & n (\%) & n (\%) & n (\%) \\
\hline Maternal age at Interview (years)* & $33.3 \pm 4.4$ & $33.2 \pm 4.3$ & $35.2 \pm 5.0$ \\
\hline$<35$ years & $772(59.8)$ & $746(61.0)$ & $26(38.2)$ \\
\hline$\geq 35$ years & $518(40.2)$ & $476(39.0)$ & $42(61.8)$ \\
\hline \multicolumn{4}{|l|}{ Maternal race/ethnicity* } \\
\hline Non-Hispanic White & $1133(87.8)$ & $1080(88.4)$ & $53(77.9)$ \\
\hline Other & $157(12.2)$ & $141(11.5)$ & $15(22.1)$ \\
\hline \multicolumn{4}{|l|}{ Medical bill payment status } \\
\hline Insurance & $1239(96.1)$ & $1173(96.0)$ & $66(97.1)$ \\
\hline Medicaid & $26(2.0)$ & $24(2.0)$ & $2(2.9)$ \\
\hline unknown & $25(1.9)$ & $25(2.0)$ & $0(0)$ \\
\hline Nulliparous & $768(59.5)$ & $727(59.5)$ & $41(60.3)$ \\
\hline$\leq$ High school education & $37(2.9)$ & $33(2.7)$ & $4(5.9)$ \\
\hline Unmarried & $106(8.2)$ & $98(8.0)$ & $8(11.8)$ \\
\hline Smoked during pregnancy & $67(5.2)$ & $65(5.3)$ & $2(2.9)$ \\
\hline No prenatal vitamins & $32(2.5)$ & $30(2.5)$ & $2(2.9)$ \\
\hline Pre-pregnancy body mass index $\left(\mathrm{kg} / \mathrm{m}^{2}\right)^{*}$ & $23.5 \pm 4.5$ & $23.3 \pm 4.4$ & $26.6 \pm 6.3$ \\
\hline Lean $(<18.5)$ & $58(4.5)$ & $57(4.7)$ & $1(1.5)$ \\
\hline Normal (18.5-24.9) & $908(70.4)$ & $876(71.7)$ & $32(47.1)$ \\
\hline Overweight (25-29.9) & $229(17.7)$ & $208(17.0)$ & $21(30.9)$ \\
\hline Obese $(\geq 30)$ & $95(7.4)$ & $81(6.6)$ & $14(20.4)$ \\
\hline
\end{tabular}

Mean \pm standard deviation (SD).

*P-value $<0.05$ from Student $t$ test for continuous variable or from Chi-Square test for categorical variables.

continuous variable, restricting the study population to women who reported sleeping $<10$ hours. In this subgroup analysis, after adjusting for maternal age and race/ ethnicity, a 1-hour increase in nightly sleep was associated with a $15 \%$ reduction in GDM risk $(\mathrm{RR}=0.85 ; 95 \%$ CI 0.69-1.05); though this association was not statistically significant. When analyses were restricted to overweight women, we noted that the GDM risk was reduced by $24 \%$ for each sleep hour increment $(\mathrm{RR}=0.76$; 95\% CI 0.57 1.00 adjusted for maternal age and race/ethnicity), but again the association was not statistically significant. Reported sleep duration before pregnancy was highly correlated with sleep duration during pregnancy ( $\rho=$ 0.92, $\mathrm{p}<0.002)$. Results were similar when analyses were repeated using maternal nightly sleep duration prior to pregnancy (data not shown).

As can be seen from the bottom panel of Table 2, maternal snoring was associated with a statistically nonsignificant 1.86-fold increased risk of GDM ( RR = 1.86; 95\% CI 0.88-3.94). An elevated risk remained after adjust- 


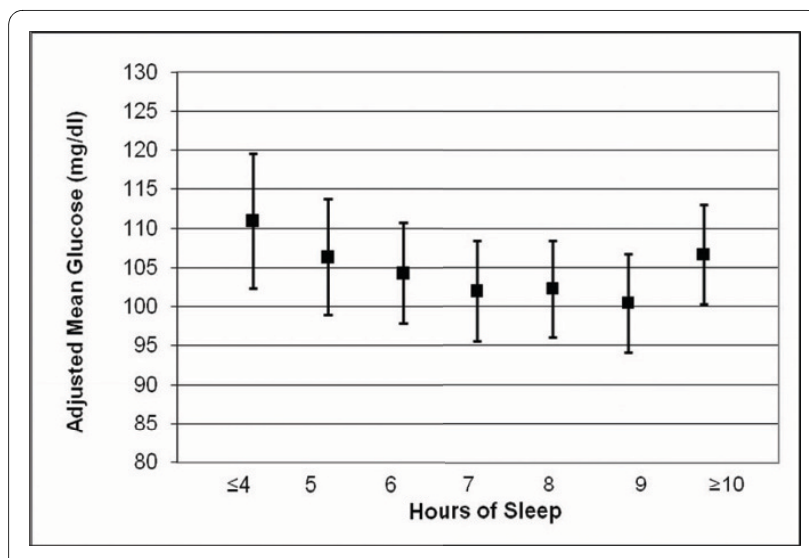

Figure 1 Maternal mean plasma glucose concentrations after a 50-g glucose challenge. Means are adjusted for maternal age and race/ethnicity. Error bars are standard errors.

ment for pre-pregnancy BMI $(\mathrm{RR}=1.54$; 95\% CI 0.71 3.35). The risk of GDM was particularly elevated among overweight women who also reported snoring during pregnancy. Compared with lean women non-snorers, those women who were both overweight and who snored had a statistically significant 6.91 -fold increased risk of GDM (RR = 6.91; 95\% CI 2.87-16.6) (Table 3).

\section{Discussion}

Using sleep duration and snoring information, provided in early pregnancy, we were able to detect associations between sleep characteristics and maternal plasma 1hour glucose concentrations after a 50-gram oral glucose challenge screening test later in pregnancy. Curvilinear relations were observed across nocturnal sleep duration categories. Additionally, glucose concentrations were statistically significantly elevated among women who snored during pregnancy; and the relative risk of GDM among overweight women who snored, compared to their nonsnoring and lean counterparts was 6.91 (95\% CI 2.8716.6). Collectively, the findings from this pilot study provides evidence consistent with the notion that glucose homeostasis in pregnancy is sensitive to maternal habitual short sleep duration and snoring during pregnancy. To our knowledge, this is the first examination of the relation between plasma glucose concentrations, GDM risk and sleep parameters (i.e., snoring and habitual sleep duration) during pregnancy.

A large literature primarily focused on men and nonpregnant women suggest that sleep loss adversely affects glucose metabolism and increases the risk of type 2 diabetes $[4,11,16,32-35]$. In their cross sectional study of 740 Canadians (323 men and 417 women), Chaput et al noted that short sleep duration ( $<7$ hours) was associated with prevalent type 2 diabetes $(\mathrm{OR}=1.58$; 95\% CI 1.13-2.31) [33]. Ayas et al, in their study of 70,026 US nurses, followed for 10 years, reported that individuals who slept $\leq$ 5 hours per night had a significantly higher risk of symptomatic incident diabetes $(\mathrm{OR}=1.34 ; 95 \%$ CI 1.04-1.72) [4]. Analysis of data from the Massachusetts Male Aging Study revealed that short sleep duration at baseline ( $\leq 5$ or 6 hours per night) was associated with elevated risk of developing incident type 2 diabetes after adjustment for covariates, including age, hypertension, smoking, selfrated health, waist circumference, education, total testosterone and cortisol [11]. Further, Gangwisch et al, in their analysis of data from the first National Health and Nutrition Examination Survey (NHANES I) noted that individuals reporting $\leq 5$ hours of sleep $(\mathrm{OR}=1.47$; $95 \%$ CI 1.03 $2.09)$ and those reporting sleeping $\geq 9$ hours $(\mathrm{OR}=1.52$; 95\% CI 1.06-2.18) had increased risks of developing dia-
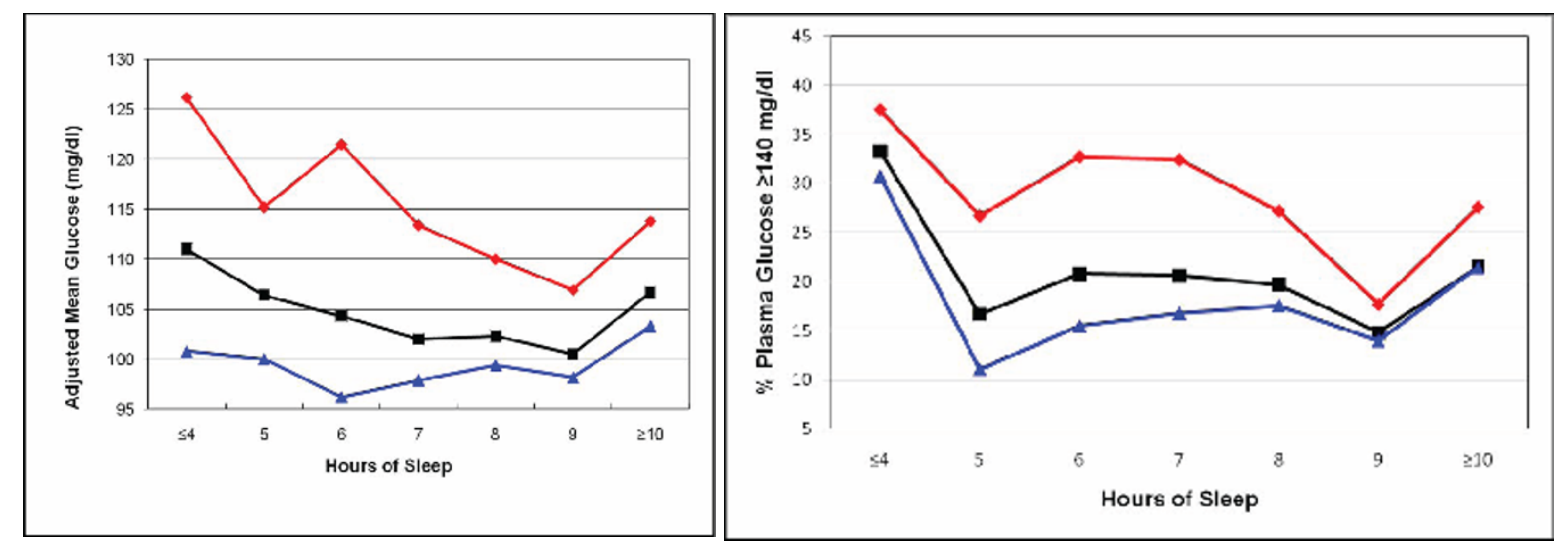

Figure 2 Maternal mean 1-hour plasma glucose concentrations after a 50-g oral glucose challenge. (a). Proportion (\%) of women with 1-hour glucose concentrations $\geq 140 \mathrm{mg} / \mathrm{dl}$ (b). Values are plotted for the entire cohort (black), lean (body mass index $<25 \mathrm{~kg} / \mathrm{m}^{2}$, blue) and overweight (body mass index $\geq 25 \mathrm{~kg} / \mathrm{m}^{2}$, red) women, respectively. 
Table 2: Adjusted risk ratio (RR) and 95\% confidence intervals (CI) of gestational diabetes mellitus (GDM) according to selfreported sleep duration and snoring during early pregnancy.

\begin{tabular}{|c|c|c|c|c|c|}
\hline & \multicolumn{2}{|c|}{ Gestational Diabetes Mellitus } & \multirow{2}{*}{$\begin{array}{c}{ }^{* A l l} \\
\\
{ }^{1} \text { Adjusted RR } \\
(95 \% \mathrm{Cl})\end{array}$} & \multirow{2}{*}{$\begin{array}{c}{ }^{*} \text { Lean } \\
{ }^{1} \text { Adjusted RR } \\
(95 \% \mathrm{CI})\end{array}$} & \multirow{2}{*}{$\begin{array}{l}{ }^{*} \text { Overweight } \\
{ }^{1} \text { Adjusted RR } \\
(95 \% \mathrm{CI})\end{array}$} \\
\hline & No $N=1222$ (n) & Yes $N=68(n)$ & & & \\
\hline \multicolumn{6}{|c|}{$\begin{array}{l}\text { Sleep duration } \\
\text { during pregnancy }\end{array}$} \\
\hline$\leq 4$ hours & 18 & 3 & $5.56(1.31-23.69)$ & $3.23(0.34-30.41)$ & $9.83(1.12-86.32)$ \\
\hline 5-8 hours & 818 & 52 & $1.99(0.89-4.47)$ & $1.28(0.47-3.43)$ & $3.47(0.79-15.22)$ \\
\hline 9 hours & 250 & 7 & 1.00--Reference & 1.00--Reference & 1.00--Reference \\
\hline$\geq 10$ hours & 129 & 6 & $1.82(0.60-5.57)$ & $1.39(0.32-5.98)$ & $2.56(0.40-16.43)$ \\
\hline Missing & 7 & 0 & & & \\
\hline \multicolumn{6}{|l|}{$\begin{array}{l}\text { Snore during } \\
\text { pregnancy }\end{array}$} \\
\hline No & 1112 & 57 & 1.00--Reference & 1.00--Reference & 1.00--Reference \\
\hline Yes & 80 & 9 & $1.86(0.88-3.94)$ & Insufficient data & $2.54(0.95-5.73)$ \\
\hline Missing & 30 & 2 & & & \\
\hline
\end{tabular}

*All refers to analysis completed on the entire cohort, and after restriction to lean $\left(<25 \mathrm{~kg} / \mathrm{m}^{2}\right)$ and overweight $\left(\geq 25 \mathrm{~kg} / \mathrm{m}^{2}\right) \mathrm{women}$, respectively.

${ }^{1} \mathrm{RRs}$ and $95 \% \mathrm{Cls}$ are adjusted for maternal age and race/ethnicity.

betes as compared to those reporting 7 hours of sleep [34]. Our findings of elevated risks of incident GDM among women reporting both long and short sleep durations in early pregnancy are consistent with these earlier reports from men and non pregnant women.

Our observations of impaired post-load glucose tolerance and increased risk of GDM among women who snore during pregnancy are also consistent with a grow- ing body of epidemiological evidence that documents markers of the severity of obstructive sleep apnea (OSA) and increased risk of type 2 diabetes in diverse populations of men and non-pregnant women from various geographic regions [32,36-38]. In a cross-sectional study of elderly Danish men and women, investigators noted that self-reported snoring was associated with abnormal glucose tolerance test results after control for confounding

Table 3: Adjusted risk ratio (RR) and 95\% confidence intervals (CI) of gestational diabetes mellitus (GDM) according to selfreporting snoring during early and pre-pregnancy overweight status.

\begin{tabular}{|c|c|c|c|c|}
\hline & \multicolumn{2}{|c|}{ Gestational Diabetes Mellitus } & \multirow[b]{2}{*}{$\begin{array}{l}\text { Unadjusted RR } \\
\quad(95 \% \mathrm{CI})\end{array}$} & \multirow[b]{2}{*}{$\begin{array}{c}\text { 1Adjusted RR } \\
(95 \% \mathrm{Cl})\end{array}$} \\
\hline & $\begin{array}{c}\text { No } \\
\mathrm{N}=1222 \\
\text { (n) }\end{array}$ & $\begin{array}{c}\text { Yes } \\
N=68 \\
(n)\end{array}$ & & \\
\hline \multicolumn{5}{|l|}{ Overweight \& Snore Status } \\
\hline Lean \& Non-Snorer & 862 & 31 & 1.00--Reference & 1.00--Reference \\
\hline Lean \& Snorer & 51 & 1 & $0.55(0.07-4.07)^{*}$ & $0.43(0.06-3.28)^{*}$ \\
\hline Overweight \& Non-Snorer & 250 & 26 & $2.89(1.69-4.96)$ & $2.85(1.65-4.92)$ \\
\hline Overweight \& Snorer & 29 & 8 & $7.67(3.24-18.1)$ & $6.91(2.87-16.6)$ \\
\hline \multirow[t]{2}{*}{ Missing } & 30 & 2 & & \\
\hline & \multicolumn{2}{|c|}{ P-value for interaction } & 0.16 & 0.13 \\
\hline
\end{tabular}

1 RRs and $95 \% \mathrm{Cls}$ are adjusted for maternal age and race/ethnicity

*The data are insufficient to adequately interpret relative risk estimates for lean snorers 
factors [36]. These findings were subsequently corroborated and extended by others, including, Al-Delaimy et al [32] who reported that self-reported regular snoring was independently associated with a 2-fold increased risk (RR = 2.03; 95\% CI 1.71-2.40) of developing type 2 diabetes over a 10-year follow-up period. Lindberg et al [37], in their cross sectional study of 6,799 Swedish women, for instance, reported that self-reported snoring and excessive daytime sleepiness was an independent risk factor for type 2 diabetes $(\mathrm{OR}=1.82 ; 95 \%$ CI $0.97-3.43)$. In a population-based Swedish study of 2,668 men followed for 10years, investigators reported that the multivariable adjusted relative risk for incident type 2 diabetes was highest for obese snorers ( $O R=7.0 ; 95 \%$ CI 2.9-16.9) than for lean non-snorers [38]. In our study we found that the adjusted relative risk of GDM was highest among overweight mothers who snored during pregnancy $(\mathrm{OR}=$ 6.91; 95\% CI 2.87-16.3) when compared with lean mothers who did not snore. In summary, available data support the notion that habitual snoring may be a risk factor for abnormal glucose metabolism. Our finding extends this literature by adding preliminary evidence that links snoring with pregnancy-related impaired glucose tolerance and GDM.

Our present pilot study has several important strengths. First, our determination of maternal sleep duration and snoring was based on reports made early during pregnancy, so reporting was not conditional on pregnancy outcomes or on signs and symptoms of GDM. Our results suggest that habitual short/long sleep duration and snoring precede the clinical diagnosis of GDM. Second, the high follow-up rate ( $>95 \%)$ minimized possible selection bias. However, several limitations merit discussion and consideration. Maternal habitual sleep duration and snoring was obtained from self-report, and thus are likely susceptible to misclassification. Reported sleep duration is known to be only moderately correlated with wrist actigraph-measured sleep duration $(\rho=0.47)$, and reports are generally longer by approximately 34 minutes for each hour of objectively measured sleep [39]. The use of self-reported snoring as a tool to detect sleep disordered breathing is well established. Investigators have shown that self-reported snoring correlates well with objective findings from nocturnal polysomnography, especially in frequent snorers [40]. Snoring that is infrequent or non-habitual has not been shown to be a useful screen for sleep disordered breathing in large epidemiologic studies $[41,42]$. It was therefore necessary to distinguish frequent snorers from infrequent snorers in our study. Our pilot study was also limited by the relatively small sample of GDM cases $(n=68)$ and the imprecision of relative risk estimates which were reflected by their wide $95 \%$ confidence intervals. A total of 251 study subjects had a post-50 gram 1-hour glucose concentration $\geq$
$140 \mathrm{mg} / \mathrm{dl}$ and thus required the follow-up diagnostic 100-gram oral glucose tolerance test (OGTT). Although qualitative results (i.e., normal/abnormal blood glucose concentrations) for the diagnostic test were available for all 251 subjects, specific glucose concentrations for each time point (i.e., fasting; 1-hour; 2-hour; and 3-hour post glucose load) were unavailable for approximately $44 \%$ of subjects. Lastly, the generalizability of our study may be limited, as our cohort was primarily comprised of NonHispanic White and well-educated women.

The pathophysiological mechanisms underlying these consistently observed associations of short sleep duration, sleep-related breathing disorders, including snoring, with altered glucose metabolism and diabetes are likely to be multifactorial $[2,43,44]$. Notably, high sympathetic nervous system activity, intermittent hypoxemia, dysregulation of the HPA axis, endothelial dysfunction and alterations in cytokine and adipokine synthesis and release have all been proposed mechanisms for these consistently observed epidemiological observations. Sympathetic hyperactivity can alter glucose homeostasis and induce insulin resistance by increasing glycogen breakdown and gluconeogenesis. Recently, investigators reported that mild sleep restriction induces marked reduction in basal glucagon concentrations [19]. Furthermore, individuals with sleep disorders may be predisposed to insulin resistance and glucose intolerance due to sleep-related dysregulation of the HPA axis with consequent elevations in serum cortisol $[16,45]$. In a community dwelling sample of 2,751 middle aged men and women, Kumari et al reported that short sleep duration and increased sleep disturbance are independently associated with diurnal slope in cortisol secretion [45].

Alternatively, cyclical hypoxemia with re-oxygenation, similar to repeated ischemia-reperfusion damage, may promote the formation of reactive oxygen species that may then elicit the release of pro-inflammatory cytokines including interleukin- 6 and tumor necrosis factor- $\alpha$ $[46,47]$. Investigators have shown that both acute total and short-term partial sleep loss results in elevated Creactive protein (CRP) concentrations [48]. Notably, investigators have reported that short sleep duration and other parameters of sleep disturbance during mid and late pregnancy are associated with increased systematic inflammation and higher stimulated levels of IL-6 [49,50]; and we have previously reported that early pregnancy CRP concentrations are predictive of incident GDM [51]. Collectively, these data suggest that sleep disturbances may augment pro-inflammatory responses that may then contribute to altered glucose metabolism. Causal biological mechanisms for the observed positive, though statistically in-significant association between long sleep duration and GDM are not clear. Some investigators, documenting similar positive association between long 
sleep duration and type 2 diabetes mellitus speculate that the association may be due in part to residual confounding by undiagnosed health conditions, co-morbid depression, unemployment, or poor general health $[1,4]$. Despite unclear mechanisms, the positive relationship between later pregnancy hyperglycemia and GDM risk were evident among women who reported short/long sleep duration and snoring in our cohort. The risks were particularly elevated among overweight women with these sleep disorders.

\section{Conclusion}

These preliminary findings suggest associations of short sleep duration and snoring with glucose intolerance and GDM. Though consistent with studies of men and nonpregnant women, larger prospective studies that include objective measures of sleep duration, sleep quality, and sleep apnea during pregnancy are needed to confirm our findings. Enhanced knowledge of possible metabolic consequences of sleep disturbances in pregnancy will likely have important clinical implications in the prevention and treatment of impaired glucose tolerance and GDM among pregnant women.

\section{Competing interests}

The authors declare that they have no competing interests.

\section{Authors' contributions}

CQ and MAW had full access to all the data in the study and take responsibility for the integrity of the data, the accuracy of the data analysis, and the decision to submit for publication. MAW conceived, designed and obtained funding for the study. CQ analyzed the data. CQ and MAW drafted the manuscript. All authors interpreted the data, critically revised the draft for important intellectual content, and gave final approval of the manuscript to be published.

\section{Acknowledgements}

This research was supported, in part, by awards from the National Institutes of Health (R01HD-055566 and R01HD-32562). The authors are indebted to the staff of the Center for Perinatal Studies for their expert technical assistance.

\section{Author Details}

${ }^{1}$ Center for Perinatal Studies, Swedish Medical Center, Seattle, Washington, USA and ${ }^{2}$ Department of Epidemiology, School of Public Health, University of Washington, Seattle, Washington, USA

Received: 29 December 2009 Accepted: 14 May 2010 Published: 14 May 2010

\section{References}

1. IOM: Institute of Medicine, Committee on Sleep Medicine and Research. Sleep Disorders and Sleep Deprivation: An Unmet Public Health Problem. Washington, DC: National Academy of Sciences Press; 2006

2. Tasali E, Mokhlesi B, Van Cauter E: Obstructive sleep apnea and type 2 diabetes: interacting epidemics. Chest 2008, 133(2):496-506.

3. Patel SR, Ayas NT, Malhotra MR, White DP, Schernhammer ES, Speizer FE, Stampfer MJ, Hu FB: A prospective study of sleep duration and mortality risk in women. Sleep 2004, 27(3):440-444.

4. Ayas NT, White DP, Al-Delaimy WK, Manson JE, Stampfer MJ, Speizer FE, Patel S, Hu FB: A prospective study of self-reported sleep duration and incident diabetes in women. Diabetes Care 2003, 26(2):380-384.

5. Ayas NT, White DP, Manson JE, Stampfer MJ, Speizer FE, Malhotra A, Hu FB: A prospective study of sleep duration and coronary heart disease in women. Arch Intern Med 2003, 163(2):205-209.
6. Resnick HE, Redline S, Shahar E, Gilpin A, Newman A, Walter R, Ewy GA, Howard BV, Punjabi NM: Diabetes and sleep disturbances: findings from the Sleep Heart Health Study. Diabetes Care 2003, 26(3):702-709.

7. Parish JM, Adam T, Facchiano L: Relationship of metabolic syndrome and obstructive sleep apnea. J Clin Sleep Med 2007, 3(5):467-472.

8. Schuster SR, Tabba M, Sahota P: Relationship between the cardiometabolic syndrome and obstructive sleep apnea. $J$ Cardiometab Syndr 2006, 1(3):204-208.

9. Meisinger C, Heier M, Loewel H: Sleep disturbance as a predictor of type 2 diabetes mellitus in men and women from the general population. Diabetologia 2005, 48(2):235-241.

10. Mallon L, Broman JE, Hetta J: High incidence of diabetes in men with sleep complaints or short sleep duration: a 12-year follow-up study of a middle-aged population. Diabetes Care 2005, 28(11):2762-2767.

11. Yaggi HK, Araujo AB, McKinlay JB: Sleep duration as a risk factor for the development of type 2 diabetes. Diabetes Care 2006, 29(3):657-661.

12. Okcay A, Somers VK, Caples SM: Obstructive sleep apnea and hypertension. J Clin Hypertens (Greenwich) 2008, 10(7):549-555

13. Ip MS, Lam B, Ng MM, Lam WK, Tsang KW, Lam KS: Obstructive sleep apnea is independently associated with insulin resistance. Am J Respir Crit Care Med 2002, 165(5):670-676

14. Levy P, Bonsignore MR, Eckel J: Sleep, sleep-disordered breathing and metabolic consequences. Eur Respir J 2009, 34(1):243-260.

15. Pack Al, Gislason T: Obstructive sleep apnea and cardiovascular disease: a perspective and future directions. Prog Cardiovasc Dis 2009, 51(5):434-451.

16. Spiegel K, Leproult R, Van Cauter E: Impact of sleep debt on metabolic and endocrine function. Lancet 1999, 354(9188):1435-1439.

17. Spiegel K, Leproult R, L'Hermite-Baleriaux M, Copinschi G, Penev PD, Van Cauter E: Leptin levels are dependent on sleep duration: relationships with sympathovagal balance, carbohydrate regulation, cortisol, and thyrotropin. J Clin Endocrinol Metab 2004, 89(11):5762-5771.

18. Spiegel K, Knutson K, Leproult R, Tasali E, Van Cauter E: Sleep loss: a novel risk factor for insulin resistance and Type 2 diabetes. JApp/ Physiol 2005, 99(5):2008-2019.

19. Schmid SM, Jauch-Chara K, Hallschmid M, Schultes B: Mild sleep restriction acutely reduces plasma glucagon levels in healthy men. $J$ Clin Endocrinol Metab 2009, 94(12):5169-5173.

20. Schmid SM, Hallschmid M, Jauch-Chara K, Bandorf N, Born J, Schultes B: Sleep loss alters basal metabolic hormone secretion and modulates the dynamic counterregulatory response to hypoglycemia. J Clin Endocrinol Metab 2007, 92(8):3044-3051.

21. Oltmanns KM, Gehring H, Rudolf S, Schultes B, Rook S, Schweiger U, Born $J$, Fehm HL, Peters A: Hypoxia causes glucose intolerance in humans. Am J Respir Crit Care Med 2004, 169(11):1231-1237.

22. Cutler MJ, Swift NM, Keller DM, Wasmund WL, Smith ML: Hypoxiamediated prolonged elevation of sympathetic nerve activity after periods of intermittent hypoxic apnea. J Appl Physiol 2004, 96(2):754-761

23. liyori N, Alonso LC, Li J, Sanders MH, Garcia-Ocana A, O'Doherty RM, Polotsky VY, O'Donnell CP: Intermittent hypoxia causes insulin resistance in lean mice independent of autonomic activity. Am J Respir Crit Care Med 2007, 175(8):851-857.

24. Polotsky VY, Li J, Punjabi NM, Rubin AE, Smith PL, Schwartz AR, O'Donnell $C P$ : Intermittent hypoxia increases insulin resistance in genetically obese mice. J Physio/ 2003, 552(Pt 1):253-264.

25. International Classification of Sleep Disorders Revised: Diagnostic and Coding Manual. Rochester, MN: American Academy of Sleep Medicine; 2000:14-17

26. Hedman C, Pohjasvaara T, Tolonen U, Suhonen-Malm AS, Myllylä W: Effects of pregnancy on mothers' sleep. Sleep Med 2002, 3(1):37-42.

27. Pien GW, Schwab RJ: Sleep disorders during pregnancy. Sleep 2004, 27(7):1405-1417.

28. ADA: Gestational diabetes mellitus. Diabetes Care 2004, 27(Suppl 1):88-90.

29. Hardin JW, Hilbe J: Generalized Linear Models and Extensions. College Station, TX: Stata Press; 2001

30. Baker RJ, Nelder JA: The Generalized Linear Interactive Modeling System release 3.77. Oxford: Oxford Numerical Algorithms Group; 1985.

31. Rothman KJ, Greenland S, Lash TL: Modern Epidemiology, 3rd version. Philadelphia: Lippincott Williams \& Wilkins; 2008:261-263. 
32. Al-Delaimy WK, Manson JE, Willett WC, Stampfer MJ, Hu FB: Snoring as a risk factor for type II diabetes mellitus: a prospective study. Am J Epidemiol 2002, 155(5):387-393.

33. Chaput JP, Despres JP, Bouchard C, Tremblay A: Association of sleep duration with type 2 diabetes and impaired glucose tolerance. Diabetologia 2007, 50(11):2298-2304

34. Gangwisch JE, Heymsfield SB, Boden-Albala B, Buijs RM, Kreier F, Pickering TG, Rundle AG, Zammit GK, Malaspina D: Sleep duration as a risk factor for diabetes incidence in a large U.S. sample. Sleep 2007, 30(12):1667-1673.

35. Knutson $\mathrm{KL}$, Van Cauter $\mathrm{E}$ : Associations between sleep loss and increased risk of obesity and diabetes. Ann N Y Acad Sci 2008, 1129:287-304

36. Jennum P, Sjol A: Snoring, sleep apnoea and cardiovascular risk factors: the MONICA II Study. Int J Epidemio/ 1993, 22(3):439-444.

37. Lindberg E, Berne C, Franklin KA, Svensson M, Janson C: Snoring and daytime sleepiness as risk factors for hypertension and diabetes in women--a population-based study. Respir Med 2007, 101(6):1283-1290.

38. Elmasry A, Lindberg E, Berne C, Janson C, Gislason T, Awad Tageldin M Boman G: Sleep-disordered breathing and glucose metabolism in hypertensive men: a population-based study. J Intern Med 2001, 249(2):153-161.

39. Lauderdale DS, Knutson KL, Yan LL, Liu K, Rathouz PJ: Self-reported and measured sleep duration: how similar are they? Epidemiology 2008, 19(6):838-845.

40. Bliwise DL, Nekich JC, Dement WC: Relative validity of self-reported snoring as a symptom of sleep apnea in a sleep clinic population. Chest 1991, 99(3):600-608.

41. Gislason T, Benediktsdóttir B, Björnsson JK, Kjartansson G, Kjeld M Kristbjarnarson $\mathrm{H}$ : Snoring, hypertension, and the sleep apnea syndrome. An epidemiologic survey of middle-aged women. Chest 1993, 103(4):1147-1151.

42. Jennum $\mathrm{P}$, Hein HO, Suadicani $\mathrm{P}$, Gyntelberg F: Risk of ischemic heart disease in self-reported snorers. A prospective study of 2,937 men aged 54 to 74 years: the Copenhagen Male Study. Chest 1995, 108(1):138-142.

43. Arnaud C, Dematteis M, Pepin JL, Baguet JP, Levy P: Obstructive sleep apnea, immuno-inflammation, and atherosclerosis. Semin Immunopathol 2009, 31(1):113-125.

44. Arnardottir ES, Mackiewicz M, Gislason T, Teff KL, Pack AL: Molecular signatures of obstructive sleep apnea in adults: a review and perspective. Sleep 2009, 32(4):447-470.

45. Kumari M, Badrick E, Ferrie J, Perski A, Marmot M, Chandola T: Selfreported sleep duration and sleep disturbance are independently associated with cortisol secretion in the Whitehall II study. J Clin Endocrinol Metab 2009, 94(12):4801-4809.

46. Vgontzas AN, Bixler EO, Chrousos GP: Metabolic disturbances in obesity versus sleep apnea: the importance of visceral obesity and insulin resistance. J Intern Med 2003, 254(1):32-44.

47. Schulz R, Mahmoudi S, Hattar K, Sibelius U, Olschewski H, Mayer K, Seeger W, Grimminger F: Enhanced release of superoxide from polymorphonuclear neutrophils in obstructive sleep apnea. Impact of continuous positive airway pressure therapy. Am J Respir Crit Care Med 2000, 162(2 Pt 1):566-570.

48. Meier-Ewert HK, Ridker PM, Rifai N, Regan MM, Price NJ, Dinges DF, Mullington JM: Effect of sleep loss on C-reactive protein, an inflammatory marker of cardiovascular risk. J Am Coll Cardiol 2004, 43(4):678-683.

49. Okun ML, Hall M, Coussons-Read ME: Sleep disturbances increase interleukin-6 production during pregnancy: implications for pregnancy complications. Reprod Sci 2007, 14(6):560-567.

50. Okun ML, Coussons-Read ME: Sleep disruption during pregnancy: how does it influence serum cytokines? J Reprod Immunol 2007, 73(2):158-165.

51. Qiu C, Sorensen TK, Luthy DA, Williams MA: A prospective study of maternal serum C-reactive protein (CRP) concentrations and risk of gestational diabetes mellitus. Paediatr Perinat Epidemiol 2004, 18(5):377-384.

Pre-publication history

The pre-publication history for this paper can be accessed here: http://www.biomedcentral.com/1472-6874/10/17/prepub doi: 10.1186/1472-6874-10-17

Cite this article as: Qiu et al., Glucose intolerance and gestational diabetes risk in relation to sleep duration and snoring during pregnancy: a pilot study BMC Women's Health 2010, 10:17

\section{Submit your next manuscript to BioMed Central and take full advantage of:}

- Convenient online submission

- Thorough peer review

- No space constraints or color figure charges

- Immediate publication on acceptance

- Inclusion in PubMed, CAS, Scopus and Google Scholar

- Research which is freely available for redistribution

Submit your manuscript at www.biomedcentral.com/submit
C BioMed Central 